\title{
O Grupo The Manifest: (re)inventando o Hip Hop
}

\author{
El grupo The Manifest: (re)inventando el hip hop
}

\author{
The Manifest Group: (re) inventing Hip Hop
}

\author{
Bóris Ximendes Bonfanti ${ }^{1}$
}

\begin{abstract}
Resumo
Nessa pesquisa é feito um estudo das identidades produzidas pelos discursos dos jovens que integram o grupo de Hip Hop The Manifest da cidade de Bagé (RS), cidade que ainda tem forte interferência de uma cultura cristã e do campo, que valoriza o esforço e as tradições. O Hip Hop tem como uma de suas características históricas os movimentos sociais de jovens negros e pobres que moravam nos guetos das cidades norte-americanas. Com a globalização o Hip Hop se espalhou pelo mundo e sofreu mudanças. Neste estudo buscou-se entender como se constituem as identidades desses sujeitos e seus discursos acerca do Hip Hop. Com base nas teorias foucaultianas e nos Estudos Culturais, foram analisados os regimes de verdade e governamentos presentes, se persistem práticas discriminatórias e excludentes em relação aos grupos que, originalmente, não se ajustavam aos padrões estabelecidos ou se esses grupos são absorvidos pelas novas configurações sociais e culturais criadas com a globalização. Na análise levou-se em conta as práticas discursivas e não discursivas, as regularidades e descontinuidades encontradas nas falas de cada jovem entrevistado. Os discursos dos sujeitos entrevistados indicaram descontinuidades quanto a compreensão das novas tecnologias como fator de visibilidade do Hip Hop. As continuidades aparecem quanto a necessidade de manter certas tradições do movimento e na valorização da dança como arte que permite aos sujeitos transgredirem os discursos preconceituosos.
\end{abstract}

Palavras-Chave: Cultura. Hip Hop. Diversidade. Discurso. Cuidado de si. Governo de si.

\section{Resumen}

En esta investigación es hecho un estúdio de las identidades produzidas por los discursos de los jóvenes que integran el grupo de Hip Hop de la ciudad de Bagé (RS), ciudad que todavía tiene fuerte interferencia de una cultura cristiana y del campo, que valora el esfuerzo y las tradiciones. El Hip Hop tiene como una de sus características históricas los movimientos sociales de jóvenes negros y pobres que vivían en los guetos de las ciudades norteamericanas. Con la globalización el Hip Hop se extendió por el mundo y sufrió cambios. En este estudio se buscó entender cómo se constituyen las identidades de esos sujetos y sus discursos acerca del Hip Hop. Con base en las teorías foucaultianas y en los estudios culturales, se analizaron los regímenes de verdad y gobernaciones presentes, si persisten prácticas discriminatorias y excluyentes en relación a los grupos que, originalmente, no se ajustaban a los estándares establecidos o si esos grupos son absorbidos por las nuevas configuraciones sociales y culturales creadas con la globalización. En el análisis se tuvo en cuenta las prácticas discursivas y no discursivas, las regularidades y discontinuidades encontradas en las conversaciones de cada joven entrevistado. Los discursos de los sujetos entrevistados indicaron discontinuidades en cuanto a la compresión de las nuevas tecnologías como factor de visibilidad del Hip Hop. Las continuidades aparecen en cuanto a la necesidad de mantener ciertas tradiciones del movimiento y en la valorización de la danza como arte que permite a los sujetos transgredir los discursos preconcebidos.

Palabras clave: Cultura. Hip Hop. Diversidad. Cuidado de sí mismo. Gobierno de sí.

\begin{abstract}
${ }^{1}$ Especialista em Educação e Diversidade Cultural; Universidade Federal do Pampa; Bagé, Rio Grande do Sul, Brasil; bonfantibxb2@outlook.com
\end{abstract}


This research studies the identities produced by the discourses of young people who are part of the Hip Hop group The Manifest of the city of Bagé (RS), a city that still has strong interference from a Christian culture and field that values the effort and traditions. Hip Hop has as one of its historical characteristics the social movements of black and poor young people who lived in the ghettos of the North American cities. With globalization Hip Hop has spread throughout the world and has undergone changes. In this study we sought to understand how the identities of these subjects and their discourses about Hip Hop are constituted. Based on Foucauldian theories and on Cultural Studies, the present regimes of truth and governance were analyzed if discriminatory and excluding practices persist in relation to groups that originally did not conform to the established standards or if these groups are absorbed by the new social configurations created by globalization. The analysis took into account the discursive and non-discursive practices, the regularities and discontinuities found in the statements of each young person interviewed. The discourses of the subjects interviewed indicated discontinuities regarding the understanding of the new technologies as a factor of visibility of Hip Hop. The continuities appear as the need to maintain certain traditions of the movement and the valorization of the dance as an art that allows the subjects to transgress the prejudiced discourses.

Keywords: Culture. Hip hop. Diversity. Speech. Care of you. Government of itself.

\section{Hip Hop: inquietações e suspeitas}

Nesse artigo pretende-se problematizar os efeitos da globalização contemporânea nos movimentos Hip Hop que, historicamente, se apresentam e são identificados como práticas de expressão e militância da juventude contra a exclusão social sofrida por negros das periferias.

Buscou-se analisar as práticas discriminatórias e excludentes em relação aos grupos Hip Hop, os discursos e os modos como praticantes dessa arte popular respondem às mudanças econômicas, sociais e culturais dos tempos presentes, por meio de um Estudo de Caso do Grupo The Manifest da cidade de Bagé (RS), realizado em 2016, no qual foi investigado: quem são os sujeitos que participam desse grupo? O que pensam sobre o Hip Hop? O que buscam com essa prática?

Os discursos dos jovens que participaram da pesquisa foram analisados com base nas teorias de Foucault, prestando atenção a certas exigências de método:

Primeiramente, um princípio de inversão: lá onde, segundo a tradição, cremos reconhecer a fonte dos discursos, o princípio de sua expansão e de sua continuidade, nessas figuras que parecem desempenhar um papel positivo como a do autor, da disciplina, da vontade de verdade, é preciso reconhecer, ao contrário, o jogo negativo de um recorte e de uma rarefação do discurso (FOUCAULT, 1996, p. 51).

Fischer (2003), seguindo a linha foucaultiana, destaca algumas atitudes epistemológicas para pesquisadores da área das ciências humanas e da educação:

Primeira delas, compreender que nossas lutas (e pesquisas) sempre têm a ver com linguagem, já que estamos continuamente envolvidos com lutas discursivas; segunda atitude, atentar para a ideia de que palavras e coisas dizem respeito a fatos e enunciados que, a rigor, são "raros", isto é, não são óbvios, estão para além das "coisas dadas"; terceira, que fatos e enunciados referem-se basicamente a práticas, discursivas e não-discursivas, as quais constituem matéria-prima de nossas investigações, seja em que campo estas se concentrem, e dizem respeito sempre a relações de poder e a modos de constituição dos sujeitos individuais e sociais; finalmente, a atitude de entrega do pesquisador a modos de pensamento que aceitem 
o inesperado, especialmente aqueles que se diferenciam do que ele próprio pensa (FISCHER, 2003, p. 02).

Portanto, práticas discursivas e não-discursivas têm uma relação complexa derivada de relações sociais de um determinado tempo histórico, único e raro. Ou seja, para descrever e compreender as práticas discursivas e não-discursivas que ocorrem num período histórico se faz necessário uma análise profunda de cada situação, buscar as regularidades e as descontinuidades de determinados discursos, analisar as relações de poder e saber que regulam os discursos, pois estas são inevitáveis e criam os modos como identidades e diferenças são produzidas.

$\mathrm{Na}$ linha foucaultiana, a única certeza que um pesquisador deve ter é que as "verdades" são sempre provisórias e que é preciso colocar em questão o dito e o vivido que se cristalizam como verdadeiros, buscando as multiplicidades de possibilidades. Para isso, há que se ter uma metodologia de análise aberta. Não se tem definido a priori as práticas discursivas e não-discursivas com as quais se trabalhará, quais ferramentas metodológicas serão usadas na pesquisa. Aponta-se apenas perspectivas metodológicas.

Assim, no estudo sobre o grupo The Manifest foram tomados os discursos dos sujeitos que o integram para problematizar os modos como identidades e diferenças são produzidas, como se governam condutas e os regimes de verdade estabelecidos nessas relações de poder e saber que criam padrões culturais éticos e estéticos, pois, essas práticas e relações geram efeitos sobre sujeitos e grupos sociais.

Com a pesquisa, percebeu-se a hibridização cultural como um efeito da globalização, pois os discursos dos sujeitos entrevistados apontaram para a necessidade de manter características históricas desses movimentos e, ao mesmo tempo, anunciavam a mobilidade permitida pelas tecnologias da informação e da comunicação como estratégia de visibilidade e novas aprendizagens.

Assim, a pesquisa feita com o grupo The Manifest leva a acreditar que os movimentos Hip Hop são afetados pelas mudanças culturais do nosso tempo, por uma globalização que aproxima várias culturas, e que faz surgir, aparentemente, uma dança mais livre, que mistura compromisso social com uma ênfase na individualidade.

A dança como expressão corporal de sonhos, desejos, sentimentos que muitas vezes são praticamente impossíveis de serem traduzidos, faz com que os jovens possam contradizer certos discursos e superar muitos preconceitos produzidos sobre seus estilos de vida.

\section{Movimentos Hip Hop: rupturas históricas}


Os movimentos sociais surgiram com o objetivo de lutar por políticas púbicas que garantam os direitos de distintos grupos e sujeitos, os quais estão posicionados socialmente pelas diferentes culturas, interligadas à política e à economia.

Hall (1997) explica como a cultura atua na constituição das identidades sociais:

Isto, de todo modo, é o que significa dizer que devemos pensar as identidades sociais como construídas no interior da representação, através da cultura, não fora delas. Elas são o resultado de um processo de identificação que permite que nos posicionemos no interior das definições que os discursos culturais (exteriores) fornecem ou que nos subjetivemos (dentro deles). Nossas chamadas subjetividades são, então, produzidas parcialmente de modo discursivo e dialógico. Portanto, é fácil perceber porque nossa compreensão de todo este processo teve que ser completamente reconstruída pelo nosso interesse na cultura; e por que é cada vez mais difícil manter a tradicional distinção entre "interior" e "exterior", entre o social e o psíquico, quando a cultura intervém (HALL, 1997, p. 06).

Desse modo os movimentos sociais assumem a identidade de ferramentas políticas de luta pelos interesses coletivos que representam:

$\mathrm{Na}$ realidade histórica, os movimentos sempre existiram, e cremos que sempre existirão. Isso porque representam forças sociais organizadas, aglutinam as pessoas não como força-tarefa de ordem numérica, mas como campo de atividades e experimentação social, e essas atividades são fontes geradoras de criatividade e inovações socioculturais. A experiência da qual são portadores não advém de forças congeladas do passado - embora este tenha importância crucial ao criar uma memória que, quando resgatada, dá sentido às lutas do presente. A experiência recria-se cotidianamente, na adversidade das situações que enfrentam. Concordamos com antigas análises de Touraine, em que afirmava que os movimentos são o coração, o pulsar da sociedade. Eles expressam energias de resistência ao velho que oprime ou de construção do novo que liberte. Energias sociais antes dispersas são canalizadas e potencializadas por meio de suas práticas em "fazeres propositivos" (GOHN, 2011, p. 237).

Contudo, na ordem global da atualidade, assim como os estados se reorganizam, também os movimentos sociais sofrem mudanças nas suas práticas. As identidades antes assumidas pelos movimentos sociais são transformadas no bojo da globalização econômica, social e cultural ${ }^{2}$. Ou seja, os movimentos sociais não se constituem mais como entidades autônomas nas relações com os estados e o mercado capitalista. Seu poder de representação das demandas sociais foi abalado pela reestruturação das relações de trabalho flexibilizadas e pelo desmonte do Estado de Bem Estar Social, o que exige dos movimentos operar com relações de negociação e/ou enfrentamento adversos. Ao mesmo tempo, a disseminação de

\footnotetext{
${ }^{2}$ Para Bauman (1999) a globalização afeta a soberania dos estados nacionais. Até um tempo atrás cada estado tinha domínio perante a economia, controlava suas riquezas. Hoje, as relações estreitas entre estado e economia transformam a vida social. Vivemos tempos de uma modernidade líquida, na qual empresas, serviços, trabalhadores e culturas não têm mais lugar fixo. As grandes empresas exploram recursos e serviços no mundo conforme os interesses financeiros, instalam postos de produção e migram sem se importar se vão gerar desempregos e sem vínculos com seus respectivos funcionários. A globalização seria a nova "desordem mundial".
} 
redes de relações de comunicação global favorece a articulação dos movimentos sociais espalhados pelo mundo todo.

\begin{abstract}
Observa-se também, no novo milênio, a retomada do movimento popular urbano de bairros, ou movimento comunitário barrial, especialmente no México e na Argentina. Todos esses movimentos têm eclodido na cena pública como agentes de novos conflitos e renovação das lutas sociais coletivas. Em alguns casos, elegeram suas lideranças para cargos supremos na nação, a exemplo da Bolívia. Movimentos que estavam na sombra e tratados como insurgentes emergem com força organizatória, como os piqueteiros na Argentina, cocaleiros na Bolívia e Peru e zapatistas no México. Outros, ainda, articulam-se em redes compostas de movimentos sociais globais ou transnacionais, como o Movimento dos Trabalhadores Rurais Sem Terra (MST) no Brasil e a Via Campesina, além da Coordenadoria Latino-americana de Organizaciones del Campo (CLOC) (GOHN, 2011, p. 337).
\end{abstract}

Nos espaços urbanos os movimentos sociais também se diversificam, surgem novos grupos, como o movimento Hip Hop nascido nos Estados Unidos, em 1929, caracterizado como dança de rua (street dance) com uma estética própria da época, num momento de grande crise econômica. Este movimento teve início principalmente por dançarinos e músicos que trabalhavam em cabarés e que, por perder seus empregos, foram as praças e ruas fazer manifestações artísticas. Nos últimos anos da década de 1960, o Hip Hop unia as práticas culturais dos jovens negros e latino-americanos nos guetos e ruas das grandes cidades. E, na década de 70, fortaleceu-se nas áreas centrais de comunidades jamaicanas, latinas e afro-americanas da cidade de Nova Iorque. Esse estilo musical conta com quatro elementos essenciais: o rap, o DJ, a breakdance e o graffiti. Outros elementos culturais que caracterizam esses grupos são as vestimentas e as gírias (SANTOS, 2012).

No Brasil o Hip Hop surgiu no final de década de oitenta. O ritmo musical chamado Rap tornou-se para os jovens das periferias urbanas um meio fecundo para mobilização e conscientização dos problemas sociais existentes. Era um modo de manifestar tudo aquilo que afetava as comunidades. Muitos grupos de rappers foram criados, ocupando um espaço de articulação e atuação no campo social, para reivindicar o direito de ser cidadão, participar do mercado de trabalho e lutar pacificamente contra a violência e a discriminação (SANTOS, 2012).

A autora também afirma que no final dos anos noventa, com muitos grupos espalhados pelo país, fortalecida por sua multiplicidade, a cultura Hip Hop, tendo o Rap como o ponto central, organizou-se num movimento de música de protesto e de combate social (Ibidem, 2012).

Ativistas brasileiros como Negra Li, Marcelo D2 e Mv Bill acreditam e defendem que o movimento Hip Hop surgiu como uma forma de protesto e repúdio às injustiças sociais. Algo muito interessante desse surgimento foi que, após alguns anos de existência, observa-se 
a força com que essa cultura está crescendo no complexo universo escolar, porque é exatamente dentro da escola que as culturas juvenis se revelam cotidianamente.

É interessante analisar que até agora o Hip Hop, segundo os autores vistos, é muito caracterizado pelas lutas sociais. Mas, será que na atualidade essa identidade persiste? Partindo de uma análise foucaultiana, é inviável acreditar na possibilidade de estagnar os tempos e espaços em que ocorrem os movimentos sociais, entre eles o Hip Hop, e usar os mesmos recursos de trinta anos atrás, por exemplo, como ferramenta de análise das práticas discursivas e não-discursivas que constituem esses grupos.

Como ressalta Miranda (2006, p. 03):

O Hip-Hop é uma manifestação sócio-cultural que nasce dentro das contradições do mundo capitalista. Um dos principais "venenos" do capitalismo é o estimulo à competição. A sabedoria do Hip-Hop foi utilizar de uma forma positiva esse "veneno" que estava levando muitos jovens a morrerem em brigas violentas entre gangues. Assim, a competição passou a ser entre as equipes de breakinge graffiti, disputando, através de suas artes, qual a melhor equipe. Essas "batalhas" tornaramse a essência do Hip-Hop no mundo. Foi oque permitiu o Hip-Hop se expandir num elevado nível de profissionalismo,tornando-se uma alternativa de sobrevivência entre seus adeptos, que passaram a assinar contratos de filmes e dispor de patrocínio de grandes marcas.

O autor chama a atenção para as mudanças sofridas nos movimentos Hip Hop no atual contexto econômico mundial, analisando as diferenças e inter-relações entre movimento e cultura Hip Hop:

1) A cultura está no movimento, mas nem sempre o movimento está na cultura; 2) Na cultura se tem artistas, no movimento se tem arte - educadores; 3) A cultura trabalha o lado profissional, o movimento trabalha o lado militante; 4) A cultura é global(mundial), o movimento é local(regionalizado); 5) A cultura é passível de se tornar moda, o movimento jamais; 6) Objetivo da cultura: divulgar o Hip Hop. O objetivo do Movimento: através da Hip Hop, transformar a realidade; 7) A cultura é instrumento do movimento, o movimento é filho da cultura; 8) Na cultura se tem quatro elementos: rap, breaking, graffite e DJ. No movimento se tem quatro e mais um: o militante; 9) Na cultura se vê atitude, no movimento se vê atitude e consciência; 10) Na cultura a "batalha" é entre os artistas, no movimento, a "batalha" é contra o sistema; 11) A cultura mobiliza, o movimento articula; 12) A cultura sem movimento é caolha e o movimento sem a cultura é aleijado (MIRANDA, 2006, p. 02).

Importante salientar que essas definições são novas e muito peculiares ao movimento Hip Hop baiano, particularmente a Rede Aiyê Hip Hop. Não é comum ver os adeptos do Hip Hop usando esses termos.

Os Movimentos Hip Hop também fazem parte dos processos de globalização do mercado e são afetados pela fluidez de informações e comunicação. Surgiu nos Estados Unidos e foi parar em vários lugares do mundo, inclusive no Brasil. O mercado também busca criar uma cultura Hip Hop, produzindo roupas, acessórios, CDs e DVs, financiando grupos e ganhando muito dinheiro com isso. 
Devido à grande evolução das tecnologias de informação e comunicação podemos "viajar sem sair do lugar". Podemos conhecer vários lugares no mundo apenas pela televisão e a rede mundial de computadores (internet), assim, temos acesso a muitas informações rapidamente, muito diferente de outrora. Nessa cultura global, a grande maioria das coisas é feita para durar pouco, para que as pessoas consumam, por isso a necessidade do mercado em estar sempre criando coisas novas.

Preto Zezé, cantor de rap do grupo Comunidade da Rima e Coordenador do Movimento Hip Hop Cultura de Rua do Ceará, esclarece como o Hip Hop é operado face ao sistema capitalista:

A dança breaking passou a fazer parte de filmes, de comerciais, de pistas de dança, invadiu os palcos dos principais teatros. O DJ passou a ser um fenômeno musical, e não mais específico da Cultura Hip Hop. O rap se tornou um dos estilos musicais mais ouvidos e vendidos de todo o planeta, participando da trilhas sonoras dos filmes, de programas deTV. É líder de audiências nas rádios. O graffiti já faz parte da vida dasgrandes galerias de arte do mundo e por aí vai. A partir dessamassificação, a indústria cultural, em particular a indústria porno-fonográfica, e todo o seu aparato (radio, mídia escrita e televisada etc.), inclui o Hip Hop, principalmente o rap, como elemento a ser produzido e comercializado pelo mercado. Esse que era, até então, uma manifestação espontânea da juventude explorada, discriminada e excluída pelo sistema. São bilhões de dólares faturados por empresas como Sony, BMG, EMI.A música rap bate todos os recordes de venda no mercadoporno-fonográfico americano, antes ocupado pelo rock. Há tempos que o rap ocupa os primeiros lugares nas premiações da MTV, e, com isso, ela ganha com o investimento dos anunciantes. Empresas como Adidas,Nike, Siemens, Pioneer, Technics, Coca-Cola e Mercedes Benz lucra mais através da publicidade feita via Hip-Hop. Essa nova etapa do mercadotraz duas conseqüências: tenta neutralizar a resistência que a CulturaHip-Hop ainda possui e acumula capital na mão das empresas multinacionais que dominam a indústria cultural (MIRANDA 2006, p. 04).

É inegável que, os movimentos sociais são afetados pelo mercado que visa produzir uma cultura de consumo, mas, ao mesmo tempo, a circulação pelo mundo de informações amplia as possibilidades de existência e inter-relação de práticas culturais que acabam por tornarem-se plurais, o que se pode observar na mistura de estilos artísticos, musicais, línguas, linguagens corporais, idiomas e outros artefatos contemporâneos. Com isso, os movimentos sociais sofrem profundas mudanças. Por isso falar em Movimentos Hip Hop e juventudes, no plural.

\section{Juventudes Hip Hop: tempos de diferença pura}

É comum a circulação de discursos que associam juventude a uma fase transitória que ocorre entre a puberdade e o pertencimento à vida adulta. Discursos das ciências modernas, como a psicologia e a biologia, onde o sujeito jovem é pensado como um ser que "progride" da fase infantil para a fase adulta, consistindo a juventude em uma fase intermediária. Assim, 
o discurso biológico e psicológico padronizou-se na cultura ocidental, definindo que o jovem é aquela pessoa quem tem entre 15 a 30 anos. Também, para as políticas públicas o critério idade é um demarcador importante na construção dessa categoria.

No discurso capitalista, a juventude é uma fase da vida marcada pela inserção social e participação na vida pública, como membro economicamente ativo da sociedade que pode contribuir com o mercado. Também, no discurso capitalista, ser jovem simboliza vigor e beleza física, coisas que com o passar do tempo perdemos. Assim o jovem se torna um modelo cultural a ser seguido. Essa visão é muito utilizada pelas mídias que incentivam as pessoas a manterem-se jovens, consumindo vários produtos e a fazerem cirurgias para ficarem mais parecidas com os corpos que são mostrados diariamente como padrões estéticos. Assim, o jovem também se torna um símbolo de consumo.

Por outro lado, a juventude também é entendida como sinônimo de crise demonstrada através de conflitos e rebeldia, estando mais vulnerável ao uso de drogas, mortes no transito, violência, entre outros, pela sua instabilidade emocional. O que há de regularidade entre esses diferentes discursos é a ideia de que a juventude é considerada uma fase de transição provocada por uma crise identitária que será resolvida na vida adulta, quando o jovem se ajusta a ordem social e cultural estabelecida.

Analisando esses discursos, percebe-se que são produzidas "verdades" sobre os jovens, colocando-os em posições fechadas e antagônicas: potencial produtivo para o mercado e rebeldes na vida social e política.

Portanto, juventude é uma construção discursiva, cultural e social muito diversificada que não pode ser definida isoladamente, mas a partir de suas múltiplas relações e contextos sociais. Nesse sentido, pensar a juventude é pensar sobre condições de gênero, raça, classe social, moradia e pertencimento. E, o principal, contextualizá-la historicamente, como integrante de uma geração específica que se relaciona com outras gerações. Por isso, como já tem sido bastante reiterado pelos especialistas, não é possível falar no jovem atual, mas nos diferentes modos de vivenciar as juventudes na contemporaneidade.

Melucci (In: FAVÉRO et al, 2007) também contribui para pensar sobre juventudes na contemporaneidade. Para ele existe uma sequência temporal no curso da vida cuja maturação biológica faz emergir determinadas potencialidades. Uma sequência temporal não precisa ser linear, apagando a anterior e eliminando as fases precedentes. O desenvolvimento é algo contínuo e as mudanças e transformações são características estáveis na vida juvenil. Portanto, na sociedade contemporânea, a juventude não é mais somente uma condição biológica, mas uma definição cultural. 
Segundo Melucci (In: FAVÉRO et al, 2007), viemos de um modelo de sociedade, o capitalismo industrial, no qual o tempo era mecânico, um tempo artificial medido pela máquina (relógio, por exemplo), não subjetivo e natural e sempre direcionado para um fim, como riqueza, progresso, salvação, etc.

Mas, no momento atual, podemos perceber que o tempo de nossas experiências pessoais é muito diferente do tempo da máquina. E com essa grande quantidade de possibilidades de tempos (televisão, internet, propagandas, redes sociais) que recebemos diariamente, vivemos em tempos diferentes. Obvio que diferentes experiências temporais não é nenhuma novidade, porém, na abrangência que temos hoje, as experiências subjetivas se tornam diferentes em relação a outras juventudes em tempos passados. As indústrias da globalização praticamente acabaram com o tempo natural do dia e noite, vivemos num mundo que sempre há novas possibilidades a qualquer hora do dia.

A definição de tempo torna-se uma questão social, um campo cultural e conflitivo
no qual está em jogo o próprio significado da experiência temporal. Como medir o
tempo? Quando será encontrado o significado 'certo' para o tempo individual e
coletivo? Como podemos preservar nosso passado e preparar o nosso futuro em
sociedades complexas? Tais questões sem respostas são alguns dos dilemas básicos
com os quais se confronta a vida humana em sociedades complexas. A juventude,
por causa das suas condições culturais e biológicas, é o grupo social mais
diretamente exposto a estes dilemas, o grupo que os torna visíveis para a sociedade
como um todo (MELUCCI in: FÁVERO et al, 2007, p. 34 ).

É necessário perceber que há uma pluralidade de juventudes possíveis de serem vividas como condição histórico-cultural, modos de subjetivação que constituem identidades e diferenças não fixas, mas móveis, transitórias, instáveis. E, toda constituição identitária deve ser analisada em suas diferentes dimensões - materiais, políticas, históricas, culturais - já que estas acarretam modos particulares de compreender as juventudes e os modos de vivê-las. Ou seja, falar em juventude é falar de uma variedade muito grande de modos de vida num mundo globalizado repleto de fatores que tornam esse conceito dinâmico.

No século XX, principalmente em sua segunda metade, produzem-se novos discursos nos quais:

\begin{abstract}
A juventude contemporânea se caracteriza muito pela pluralidade de expressões, pela flexibilidade e mobilidade de suas trajetórias, pela fluidez e abertura do sentido que constroem suas próprias vidas. Fixados mais no tempo presente, não mais esperam "colher os frutos" no futuro ou confiar nas promessas do passado. Produzem suas experiências cotidianas, novos modos de ser e estar na sociedade, ampliando suas significações e práticas e (re)significando aquilo que nomeamos juventude (AMARAL, 2015, p. 42).
\end{abstract}

Talvez o grande desafio nesse momento histórico seja buscar novos meios de compreender o mundo, novas formas de operar com as verdades até então estabelecidas. Um pensamento que leve em conta as diferentes experiências de vida, que amplie as formas de ver 
o mundo, que nos ajude a pensar de outro modo. O próprio pensamento se torna objeto de pesquisa.

Conforme Corazza (2009) vivemos um tempo desafiador, tempo esse que é contexto dos jovens contemporâneos:

\begin{abstract}
Chamo-o tempo de Desafio da Diferença Pura porque suas concepções e práticas atestam a existência dos diferentes, que povoam nossas casas e ruas, escolas e salas de aula, dias e noites. Diferentes, que são os homossexuais, negros, índios, pobres, mulheres, loucos, doentes, deficientes, prostitutas, marginais, aidéticos, migrantes, colonos, criminosos, infantis-adultos, todos os que foram denominados minorias, isto, todos os Sem...; os quais, por tanto tempo, ficaram borrados e excluídos, calados e subordinados, dominados e pisoteados pela lógica da IdentidadeDiferença, mas que, hoje, por força de suas próprias lutas, são diferentes em simesmos, essencialmente-outros, não-idênticos, outros-diversos, puros em si mesmos, não aceitando mais serem vistos como vítimas ou culpados, fontes do mal, ou desvios a serem tolerados; e para que nunca mais suas diferenças sejam governadas, traduzidas, calibradas, reparadas ou integradas ao velho Princípio da Identidade Universal (CORAZZA, 2009, p. 14).
\end{abstract}

Na perspectiva da diferença pura não se opera um discurso de aceitação ou tolerância do outro, mas no deslocamento de uma posição fixa que estabelece quem somos e quem são os outros. Assim, se coloca em discussão certos discursos que criam identidades e diferenças padronizadas e lugares hierárquicos para cada grupo de sujeitos, como os jovens dos movimentos Hip Hop.

\title{
4. Com a palavra: o Grupo The Manifest
}

O Grupo The Manifest foi criado em 2006, tendo, em média, vinte integrantes, entre homens e mulheres que estão no movimento a mais de dez anos. Foram entrevistadas seis pessoas do Grupo, quatro homens e duas mulheres. Esses sujeitos estão na faixa etária entre 20 e 29 anos e possuem profissões diversas, tais como: estudante, açougueiro, auxiliar de hotelaria, bailarino, e um deles estava desempregado. Todos moram na periferia da cidade de Bagé (RS).

A seguir apresenta-se a análise dos discursos proferidos pelos sujeitos pesquisados, onde emergiram as categorias identidades, tradição, inovação, dança, afetos.

\subsection{Identidades Hip Hop nos tempos e espaços vividos}

Enquanto um dos sujeitos relata sua experiência no grupo em razão de uma identificação vital, com o Hip Hop, outros manifestam que foram movidos pela casualidade, busca de lazer, laços afetivos e prazer pela arte da música e da dança:

É tipo pra mim sempre teve no sangue, já ouvia James Brow em casa né, já ouvia Michel Jackson, sou do tempo do vinil, então aquilo me contagiava, então eu sabia que eu podia participar e podia fazer alguma coisa assim como a gente age, age como graffite, age como DJ, age com a dança né, até hoje a gente possui um lugar 
pra gravar as músicas das MC's, então o Hip Hop sempre teve presente em tudo, e hoje ele tá mais forte na mídia, na moda, nas roupas né, então sempre fez parte da minha vida assim. (Heron)

Na escola, um deles dava aula, assim projetos sociais assim, e ai eu fui, comecei a ir, comecei a gostar, comecei a conhecer o grupo, ai quando vi o The Manisfest, conheci o Sanonoca, que é, que é o coordenador do grupo, né, que é pai, que é pai de um dos guris ali, e tipo eu vi que ele assim dedicava a vida dele a, ele acreditava no futuro pros filhos deles, sabe, acreditava, que, cara um pai que acredita na dança de rua, que acredita no Hip Hop que acredita que aquilo vai dar um rumo pros filhos dele, eu pensei, cara eu posso viver isso também, e nisso comecei, a ir nos ensaios, comecei a gostar, comecei a conhecer.(Ana)

Percebe-se que em nenhum desses discursos o Hip Hop é visto como um protesto contra as desigualdades sociais e a exclusão, que é umas das principais características históricas desse movimento. Mesmo o sujeito que afirma identificar-se totalmente com o Hip Hop citando músicos que fizeram parte do passado, como James Brow e Michel Jackson, refere-se as mudanças sofridas pelos movimentos na atualidade, com a influência da mídia e do mercado de consumo.

Logo, os discursos remetem a uma ruptura com uma identidade fixada na tradição do Hip Hop, apontando para uma produção identitária multifacetada, tanto no que se referem aos movimentos Hip Hop, quanto aos significados que os sujeitos criam para justificar sua própria inserção no grupo The Manifest. Os discursos dos sujeitos entrevistados reforçam o entendimento de que a produção de identidades e diferenças é fluída e transitória, escapando à lógica de fixidez instituída pelo pensamento científico moderno.

Fixar uma determinada identidade como a norma é uma das formas privilegiadas de hierarquização das identidades e das diferenças. A normalização é um dos processos mais sutis pelos quais o poder se manifesta no campo da identidade e da diferença. Normalizar significa eleger - arbitrariamente - uma identidade específica como o parâmetro em relação ao qual as outras identidades são avaliadas e hierarquizadas. Normalizar significa atribuir a essa identidade todas as características positivas possíveis, em relação às quais as outras identidades só podem ser avaliadas de forma negativa. A identidade normal é "natural", desejável, única. A força da identidade normal é tal que ela nem sequer é vista como uma identidade, mas simplesmente como a identidade (SILVA In: SILVA; HALL; WOODWARD, 2014, p. 83).

As identidades dos grupos Hip Hop produzidas na contemporaneidade estão circunstanciadas pela globalização do mercado capitalista e da cultura de massas que visam criar modismos. Assim, as diferenças culturais são capturadas e padronizadas para favorecer a lógica do consumo.

Tal constatação é feita na fala dos entrevistados:

Hoje o Hip Hop não é mais o mesmo de antes, tá muito "modinha", como a gente fala lá no grupo, muito "modinha", às vezes a gente vai pra um festival, aí a gente já vê que, não é mais o Hip Hop de antigamente, tipo, mais dança, hoje, é mais, como é que eu posso te explicar, ah sei lá, tipo, as pessoas não dançam mais, tipo, na pegada, não tem mais aquela vontade, eles vão pra o festival pra aparecer mesmo, por causa de nome ou alguma coisa assim. (Paulinho) 
Contudo, alguns dos sujeitos entrevistados manifestam a necessidade de manter determinadas características históricas do Hip Hop sem negar as possibilidades de disseminação dessas práticas culturais e de ampliação das informações e recursos tecnológicos trazidos com a globalização e que beneficiam os grupos, ao relatarem:

\begin{abstract}
Ah, tipo os guris mesmo, hoje eles estão mais, tem mais coisa na internet, hoje tá mais fácil de conseguir música, e aula a gente vê pela internet, tem contato com pessoas de outros países né, a gente consegue expandir assim, e o Hip Hop hoje, claro antigamente era mais quem gostava mesmo sabe, e o hoje assim ele tá, ele tá bastante, bem universal todo mundo gosta e tal, mas ainda tem ah, a gente sente ainda uma falta daquela coisa do Hip Hop de raíz, as músicas, a gente sente a diferença, tem a, claro tem as coisas assim que são assim meio moda, que aí foge um pouco da cultura Hip Hop original, assim sabe, e o propósito do The Manifest, que, é seguir, levar o Hip Hop tradicional, é.. o Breack, levar essas coisas, manter sabe, ah... manter essas raízes, porque o The Manisfest surgiu na época, Bagé não conhecia isso, e The Manisfest trouxe isso pra Bagé, e a gente quer se adaptar ao mundo de hoje, mas sem esquecer das nossas raízes, então é isso, tipo, e eu, e eu tô nessa caminhada junto, pra... levar, que acredito que através da arte, da dança a gente consegue mudar muita coisa.(Ana)
\end{abstract}

Logo, os discursos dos sujeitos pesquisados apresentam regularidades quanto a ideia de manter viva determinadas características históricas da cultura Hip Hop. As descontinuidades discursivas aparecem na discordância quanto aos efeitos positivos e negativos de visibilidade criados pela globalização sobre os movimentos e a cultura Hip Hop. Essas descontinuidades nas práticas discursivas dos sujeitos entrevistados em torno da produção de regimes de verdade atribuídos ao Hip Hop indicam um processo de hibridização cultural.

O processo de hibridização confunde a suposta pureza e insolubilidade dos grupos que se reúnem sob as diferentes identidades nacionais, raciais ou étnicas. A identidade que se forma por meio do hibridismo não é mais integralmente nenhuma das identidades originais, embora guarde traços delas (SILVA In: SILVA; HALL; WOODWARD, 2014, p. 87).

Logo, a produção identitária dos sujeitos Hip Hop analisados aponta para um jogo de relações de poder e saber no qual a disputa se dá pelo legitimação de um regime de verdade que oscila entre manter o Hip Hop com certas características históricas do movimento e incorporar mudanças para aumentar a visibilidade e projeção dessa cultura renovada, como um estilo artístico e musical que se expande para além dos tempos e espaços tradicionais.

\title{
4.2. Hip Hop, ética e afetos
}

Nas falas de alguns dos sujeitos pesquisados foi destacado o preconceito relacionado ao Hip Hop:

O jeito que eles se dedicavam, pra aquilo ali, sabe, encaravam o preconceito que, hoje é alto, mas naquela época era mais ainda, porque era uma coisa que, ainda mais em Bagé que é uma cidade pequena, era coisa... assim... oh... até hoje assim, se eu 
disser, ah eu trabalho no comércio, assim que me vê assim de roupinha arrumadinha, não sabe que eu... que eu faço dança de rua, né, mas aí quando eu falo as pessoas já olham assim meio de canto, já... já, já tipo, já pensam Ah! Ela... como é que é? Cara de santa, de santa não tem nada, dança de rua, já é... ah deve de beber alguma coisa, assim, ainda tem esse preconceito, né, lá naquela época mais, e com meus pais também era... era, pior... nossa! Mas eles demoram anos pra aceitar, até hoje não aceitam muito. (Ana)

Quando os sujeitos entrevistados se posicionam sobre as relações de preconceito vividas pelos movimentos Hip Hop na sociedade em que predomina uma cultura e uma ação política elitista, estão presentes nesses discursos os modos como se produz o governo dos outros, pois outros são aqueles que não se enquadram no padrão de normalidade instituído.

Ao mesmo tempo, os sujeitos entrevistados falaram na arte do Hip Hop como uma prática que os conduz a adequarem-se ao meio social em que vivem, pois os afasta de riscos, como a criminalidade. Também dizem ser necessário o reconhecimento social e que suas relações melhoram com a autoconfiança que adquirem, quando afirmam:

Já pensei em desistir assim, mas hoje eu vejo que é uma coisa que faz parte de mim, sabe, que me fez, que eu não sei, se eu aí, talvez eu teria ah, como seria minha vida se eu não tivesse entrado na dança de rua, porque lá, eu aprendi muita coisa, o valor, os valores, tipo a ser humilde, de saber ganhar, de saber perder, de saber ganhar críticas, ah.. receber elogios, aprender sabe, a se dedicar nas coisas que a gente mais gosta, a dar as coisas simples, assim sabe, que a gente não dá tanto valor.(Ana)

Logo, os discursos dos sujeitos entrevistados apontam para a constituição de uma ética das relações de governo de si e dos outros que visam tornar o Hip Hop uma prática aceitável na vida social e cultural pela quebra de preconceitos que associam esses movimentos culturais a desvios de conduta num padrão ético normalizador.

Foucault (2006) analisa o governo de si como as práticas do sujeito sobre si mesmo que conduzem a uma formação ética para adequar-se às regras e códigos morais vigentes na cultura e na sociedade da qual se faz parte ou para transformá-la. Contudo, o sujeito não está condicionado aos padrões sociais e culturais vigentes, ele pode assumir certa liberdade na condução de sua própria vida. Assim, o governo de si é produzido na relação com os outros, mas sem anular as possibilidades de ação do próprio sujeito na constituição de sua identidade.

Os discursos dos sujeitos entrevistados apontaram as práticas vivenciadas pelo grupo através da dança como produção de vivências corporais e artísticas que desenvolvem criatividade, força, equilíbrio, disciplina, afetividades:

Eu olhei assim, Bah! Eu só via em TV, aí eu vi aquele grupo fazendo um monte de passos legais, (...) eu gosto muito dessa área, do breack, aí quando eu vi uma menina fazer, ah!! dançando breack, aí eu fiquei assim: Cara, se ela faz, ah!... sim, é possível, (...) é uma coisa, legal assim. (Ana)

Realmente é o amor pela dança. Como desde os dez anos eu danço, eu acho que... eu parei um tempo até também, fiquei um tempo sem dançar, e acabei voltando a 
dançar porque é o que eu gosto de fazer, eu não... acho que não tem outra coisa que eu sei fazer melhor do que dançar. (Marcinho)

Embora haja as disputas de performances nos torneios de Hip Hop, os sujeitos do grupo The Manifest enfatizam o prazer na vivência da dança pelo movimento corporal que os desafia a experimentar, criar, expressarem-se, romperem seus limites. A valorização das experiências com a dança indica uma ruptura com o discurso científico moderno que despreza o sensível em nome da razão e da filosofia cristã contrária aos prazeres corporais. O corpo, suas expressões e movimentos também produzem os sujeitos e seus modos de existência.

Em muitos torneios de dança Hip Hop os bboys realizam suas performances com passos considerados clássicos, o que os leva a manter as tradições. Mas, as disputas não visam apenas a competição. Como aparece no relato abaixo, os torneios tornam-se espaços de interação, de divertimento, de vivências de amizades e afetos entre os sujeitos e os grupos:

\footnotetext{
Antes de entrar no grupo, na real eu nem sabia que existia dança, aconteceu por uma acaso mesmo, como eu disse de eu ir no Esporte e Lazer pra jogar futebol e acabei descobrindo dança. Quando eu... o primeiro impacto, foi, que eu vi é... jovens que eram mais velhos do que eu, mas eram jovens também, se divertindo ali, era uma forma de disputa, mas uma forma de disputa amigável, em que no final todo mundo se abraçava, dava risada, e pra mim o que eu pensava daquilo era uma forma de divertimento mesmo. (Marcinho)
}

O amor pelo Hip Hop foi um enunciado recorrente nos discursos dos entrevistados. Disseram que se identificam como dançarinos de Hip Hop. Mas eles são bem mais que isso. São trabalhadores, estudantes, pessoas que lutam para viver independentemente das dificuldades que enfrentam e isso tudo transforma suas vidas e culturas.

É de grande relevância a atuação do Grupo The Manifest na cidade de Bagé, carente de políticas públicas para a juventude e que ainda conserva padrões culturais elitistas e preconceituosos em relação à cultura e a arte Hip Hop.

Não se trata de negar no contexto local a cultura cristã e tradicionalista, que valoriza muito o esforço e sacrifício, mas abrir e fortalecer espaços para a manifestação da pluralidade cultural, vivenciar a diversidade através da convivência com as diferentes culturas, grupos e sujeitos, incluindo o Hip Hop.

\section{Considerações Finais: alguns indícios do não-dito}

Em tempos de globalização os movimentos Hip Hop se (re)inventam e (re)inventam seus lugares, denunciam a desigualdade social e se mesclam com outras culturas, reivindicando reconhecimento e visibilidade.

Resistem ao preconceito que menospreza as artes populares em regiões onde a cultura cristã associa a vida e o trabalho ao sacrifício, "verdades" que segregam grupos, discriminam 
sujeitos que escapam aos padrões culturais estabelecidos. As roupas largas e bonés, as gírias dos "manos" e das "minas" causam o estranhamento de jovens que tomam as ruas e espaços públicos, movimentos da periferia que ocupam os centros urbanos.

Assim, o Hip Hop (re)inventa o espaço e o tempo presente. A tradição se mistura com a inovação. Diferentes culturas se entrecruzam num jogo de forças que embelezam e tornam a cidade mais viva. São as diferenças que causam espanto, movimento, mudança.

No Hip Hop, o corpo fala e fala muito enquanto dança. Os movimentos corporais expressam sonhos, desejos, sentimentos que muitas vezes são praticamente impossíveis de serem traduzidos. A dança faz com que os jovens possam contradizer certos discursos e resistir a uma subjetivação tematizada negativamente, resistem aos jogos de poder nas relações sociais, resistem aos discursos que os inferiorizam. Não é uma resistência simplesmente como modo de oposição, mas como criação, pois através da dança constituemse novas subjetividades.

Com o Hip Hop, sonhos, desejos, liberdade, afetos podem ser vivenciados de um jeito bem particular. Novos modos de relacionar-se socialmente numa condição dual: coletiva, por que é exercida com outras pessoas, e singular, fruto das operações do indivíduo sobre si mesmo, (re)criando modos de vida.

\section{Referências}

AMARAL, Márcio. Jovens de periferia e arte de construir a si mesmo: experiência de amizade, dança e morte. Tese (Doutorado). Universidade Federal do Rio Grande do Sul, Faculdade de Educação, Programa de Pós-Graduação em Educação, Porto Alegre, 2015.

BAUMANN, Zigmund. Globalização: As consequências humanas. Rio de Janeiro: Jorge Zahar Editor, 1999.

CORAZZA, Sandra Mara. A educação do séc.XXI: desafio da diferença pura. Ariús, Revista Brasileira de Ciências Humana e Artes, v. 15, n. 01, jan./jun. 2009, p. 9 -16.

FISCHER, Rosa. Foucault revoluciona a pesquisa em educação? Perspectiva, Florianópolis, v. 21, n. 02, p. 371-389, jul./dez. 2003. Disponível em: https://periodicos.ufsc.br/index.php/perspectiva/article/download/9717/8984. Acesso em: 24 de abril de 2017.

FOUCAULT, Michel. A ordem da discurso. $3^{\circ}$ ed. São Paulo: Edições Loyola, 1996.

GOHN, Maria da Glória. Movimentos sociais na contemporaneidade. Revista Brasileira de Educação, v. 16 n. 47, maio/ago. 2011. Disponível em: http://www.scielo.br/pdf/rbedu/v16n47/v16n47a05.pdf. Acesso em: 18 de maio de 2017. 
HALL, Stuart. A centralidade da cultura: notas sobre as revoluções do nosso tempo. Educação \& Realidade. Porto Alegre: UFRGS/FACED, v.22, n.2, jul/dez, 1997, p. 15-46.

MELUCCI, Alberto. Juventude, tempo e movimentos sociais. In: FÁVERO, O.; et al. Juventude e Contemporaneidade. Coleção Educação para todos. Brasília: UNESCO, MEC, ANPED, 2007, p. 29-46.

MIRANDA, Jorge Hilton de A. Relação de mercado e trabalho social no Hip Hop. Caderno do CEAS, n. 223, jul./set. 2006, p. 47-58. Disponível em: https://cadernosdoceas.ucsal.br/index.php/cadernosdoceas/article/view/165. Acesso em: 24 de novembro de 2016.

SANTOS, Núbia Oliveira dos. Hip Hop como manifestação cultural: protagonismo juvenil em Rio Verde - Goiás. Dissertação (Mestrado). Universidade Católica de Goiás, Programa de Pós-Graduação em História, Goiânia, 2012.

SILVA, Tomaz Tadeu da. A produção social da identidade e da diferença. In: SILVA, T. T. da; HALL, Stuart; WOODWARD, K. (orgs). Identidade e diferença: A perspectiva dos Estudos Culturais. $7^{a}$ edição. Rio de Janeiro, Vozes, 2014, p. 73-102. 